Revue d'histoire de l'enfance " irrégulière »

Le Temps de l'histoire

16 | 2014

La part scolaire : jeunesse irrégulière et école $\left(\mathrm{XIX}^{\mathrm{e}}\right.$ $\mathrm{XX}$ siècles)

\title{
Mathieu Peter, Les orphelinats du Tarn sous la Troisième République
}

Amélie Nuq

\section{CpenEdition}

Journals

Édition électronique

URL : https://journals.openedition.org/rhei/3699

DOI : $10.4000 /$ rhei.3699

ISBN : 978-2-7535-4019-4

ISSN : $1777-540 \mathrm{X}$

Éditeur

Presses universitaires de Rennes

Édition imprimée

Date de publication : 30 octobre 2014

Pagination : 202-206

ISBN : 978-2-7535-3558-9

ISSN : $1287-2431$

Référence électronique

Amélie Nuq, "Mathieu Peter, Les orphelinats du Tarn sous la Troisième République », Revue d'histoire de l'enfance « irrégulière » [En ligne], 16 | 2014, mis en ligne le 30 octobre 2014, consulté le 08 septembre 2021. URL : http://journals.openedition.org/rhei/3699; DOI : https://doi.org/10.4000/rhei.3699

Ce document a été généré automatiquement le 8 septembre 2021.

(C) PUR 


\title{
Mathieu Peter, Les orphelinats $d u$ Tarn sous la Troisième République
}

\author{
Amélie Nuq
}

\section{RÉFÉRENCE}

Mathieu Peter, Les orphelinats du Tarn sous la Troisième République, Albi, Presses du Centre universitaire Jean-François Champollion, 2012, 357 p., ISBN : 978-2-36170-040-9

1 Ce livre est issu d'une thèse de doctorat d'histoire du droit et des institutions, soutenue en 2009. Son auteur souhaite contribuer à l'histoire de l'action menée par le secteur privé dans le domaine de l'enfance assistée, le champ de l'assistance publique étant mieux connu (comme en témoigne l'étude récente d'Isabelle Le Boulanger, consacrée aux pupilles de l'Assistance publique des Côtes-du-Nord, ou l'ouvrage de référence d'Ivan Jablonka, Ni père ni mère : histoire des enfants de l'Assistance publique, 1874-1939). « Le temps des orphelinats " s'ouvre autour de 1825 et connaît son apogée dans la deuxième moitié $\mathrm{du} \mathrm{XIX}^{\mathrm{e}}$ siècle ; il concorde avec le renouveau spirituel qui caractérise le siècle, les communautés religieuses dominant largement la direction des orphelinats. Mathieu Peter part du constat selon lequel tout le monde sait, ou croit savoir, ce qu'est un orphelinat : un établissement prenant en charge des enfants ayant perdu leurs parents. Pourtant, il y a paradoxalement peu d'orphelins dans les orphelinats, qui accueillent surtout des enfants pauvres. Même si la pension acquittée par la famille est dans ce cas souvent dérisoire, elle contribue à brouiller la frontière entre les institutions charitables que sont les orphelinats et des établissements éducatifs d'une autre nature, comme les pensionnats. Mathieu Peter propose la définition suivante: pour lui, les orphelinats sont des «établissements charitables spéciaux, d'initiative privée et à caractère confessionnel, recueillant et éduquant des enfants en situation familiale malheureuse » (p.29). Il pointe du doigt le vide juridique entourant de telles institutions, qui sont définies par un cadre règlementaire par défaut et emprunté à d'autres structures telles que les associations, les fondations ou les congrégations. Dans ce contexte, au XIX ${ }^{e}$ siècle, nombre d'orphelinats sont créés et fonctionnent en-dehors 
de toute intervention étatique, généralement au sein de structures préexistantes comme les hôpitaux-hospices ou les maisons conventuelles. Les orphelinats ayant intrinsèquement des contours imprécis, il est extrêmement difficile de les répertorier : c'est pourtant la tâche à laquelle s'est attelé Mathieu Peter qui, pour ce faire, a choisi un cadre géographique restreint, le Tarn, et a essentiellement eu recours aux séries $\mathrm{X}$ et $\mathrm{V}$ des archives départementales (relatives à l'assistance et aux cultes). Son livre, qui se situe à la croisée du droit et de l'histoire locale, décrit l'évolution du dispositif législatif et analyse la façon dont celui-ci est appliqué dans le Tarn, donnant parfois au lecteur l'impression d'une juxtaposition de chroniques monographiques portant sur chacun des orphelinats. Par ailleurs, on pourra déplorer le fait que tous les critères scientifiques de présentation d'un ouvrage d'histoire ne soient pas respectés: le numéro des pages ne figure pas dans le sommaire; on ne peut se référer à une bibliographie globale recensant les références citées en note de bas de page ou à une carte du département du Tarn, qui aurait utilement permis de situer les nombreux établissements mentionnés.

2 Le plan de l'ouvrage comprend deux parties divisées en deux titres, eux-mêmes scindés en deux chapitres, regroupant à leur tour deux sections: cette structure binaire, traditionnelle du droit français, ne permet pas d'éviter des redites et contribue à rendre la démonstration rigide et peu dynamique. La première partie, intitulée « La permission de recueillir ", décrit l'évolution de l'attitude des autorités vis-à-vis des quelque 35 orphelinats du Tarn, catholiques pour l'essentiel. Ces établissements sont longtemps considérés avec bienveillance par l'État, qui n'est pas en mesure de venir en aide à l'enfance malheureuse. Ils sont néanmoins contrôlés, dans la lignée de la tutelle traditionnellement exercée par l'État sur la charité privée, puisqu'ils doivent être reconnus par les autorités. L'aspect charitable des orphelinats dérange peu les républicains quand surgit la question congréganiste, au tout début du $\mathrm{xx}^{\mathrm{e}}$ siècle; cela explique que, bon gré mal gré, les établissements parviennent à subsister. D'autre part, les orphelinats prétendent proposer un cadre complet d'éducation, les occupations des enfants se partageant entre l'enseignement primaire et la formation professionnelle. C'est à cet aspect éducatif qu'est consacrée la deuxième partie de l'ouvrage ("L'interdiction d'éduquer »). Mathieu Peter montre qu'une fois installée l'école laïque, gratuite et obligatoire de la III ${ }^{e}$ République, c'est la mission d'enseignement primaire des orphelinats qui est menacée: les enfants doivent désormais être scolarisés à l'extérieur de l'établissement, dans des écoles publiques. Néanmoins, l'État tolère la mission d'apprentissage assurée par les orphelinats dans la mesure où il n'a pas encore les moyens de proposer un enseignement technique et professionnel digne de ce nom. Le but est de rendre les garçons utiles à la société et de faire des filles de bonnes épouses, mères, domestiques ou religieuses.

3 Le travail de Mathieu Peter vise à étudier l'histoire des orphelinats du Tarn à la lumière des rapports que ceux-ci entretiennent avec l'État. Il s'agit d'une question cruciale dans la mesure où la protection de l'enfance symbolise l'interaction de la charité privée et de l'assistance publique: la première suppléant depuis longtemps les carences de la seconde, la transition de l'une à l'autre est complexe. Au XIX siècle, l'État cherche en effet progressivement à s'approprier des domaines jusque-là détenus par les communautés religieuses; à terme, l'école se laïcise et l'hôpital se médicalise. Dans ce contexte, l'affrontement idéologique entre l'Église et l'État n'épargne pas ces institutions mixtes, à la fois charitables et enseignantes, que sont les orphelinats. Cette 
ambiguïté est au cœur même de l'histoire de ces établissements sous la III République. En effet, suite à l'adoption de la loi du 7 juillet 1904, les congrégations religieuses n'ont plus le droit d'enseigner : elles cherchent donc à démontrer la mixité de leurs œuvres, à la fois hospitalières et enseignantes, pour éviter la liquidation. Le gouvernement, de son côté, exploite l'ambiguïté des orphelinats en insistant sur leur caractère enseignant. L'étude empirique menée par Mathieu Peter a ainsi pour mérite de donner à voir, au niveau local, la façon dont la législation anticléricale est reçue. Les congrégations religieuses réagissent en effet de façons diverses au processus de sécularisation de la société, certaines faisant preuve d'une faculté d'adaptation et de modernisation certaine: selon les cas, la législation est appliquée entièrement, partiellement ou pas du tout, immédiatement ou avec retard... La loi de 1904 engendre par exemple le développement d'écoles libres permettant aux religieux, par des mécanismes juridiques détournés, de continuer à enseigner. Dans le Tarn, $80 \%$ des élèves des écoles congréganistes qui ont été fermées ne se rendent ainsi pas dans des écoles publiques. Dans les villages du Gos et de Massac, lorsque les Sœurs de SaintJoseph et les Filles de Jésus consentent à envoyer les pensionnaires de leur orphelinat à l'école du village, c'est en réalité pour les orienter vers un établissement qu'elles dirigent. Mathieu Peter insiste sur le fait que les autorités ne sont pas dupes des moyens utilisés par les congrégations pour continuer à exister ; mais dans les contrées reculées du département rural et isolé qu'est le Tarn, les relations entre les municipalités et les communautés religieuses, qui sont traditionnellement bonnes, surclassent la pression anticléricale.

4 L'auteur met en évidence une autre spécificité locale, à savoir la ligne de fracture qui sépare les orphelinats catholiques et protestants. Le département du Tarn compte deux foyers protestants, la Montagne Noire et les Monts de Lacaune, près de Castres et de Mazamet. Quatre orphelinats protestants sont créés dans la lignée du mouvement du «Réveil » qui, au début du XIX ${ }^{e}$ siècle, s'est proposé de réactiver la foi en menant des actions concrètes dans les domaines de l'éducation, de la santé et de la pauvreté. Il s'agissait de prendre pied dans un domaine jusque-là monopolisé par l'Église catholique. Cette concurrence et cette émulation expliquent d'ailleurs, selon Mathieu Peter, le fait que plus de trente orphelinats aient été créés dans le seul département du Tarn. La gestion des institutions de bienfaisance protestantes est plus rigoureuse que celle des établissements catholiques: la reconnaissance du gouvernement est par exemple systématiquement demandée (les orphelinats protestants de Castres et de Brassac sont les deux seuls établissements tarnais qui aient été reconnus d'utilité publique), ce qui permet à la religion réformée de tisser des liens étroits avec les autorités. De fait, la contestation anticléricale semble épargner les orphelinats protestants, dont le personnel est très attentif à l'instruction primaire et n'hésite pas à envoyer les enfants à l'école publique. Néanmoins, notons que cette ligne de fracture confessionnelle n'est pas opératoire lorsqu'il s'agit de la prise en charge des filles: "qu'ils soient confessionnels ou laïques, congréganistes ou protestants, privés ou publics, tous les orphelinats sans exception préparent les jeunes filles aux travaux de l'aiguille et du ménage » (p. 292).

5 Le lecteur historien pourra déplorer le flou chronologique qui entoure la période étudiée par l'auteur: contrairement à ce qu'indique le titre de l'ouvrage, l'étude ne porte pas sur la Troisième République (1870-1940) mais sur un long xIX ${ }^{e}$ siècle qui s'achèverait avec l'application des lois républicaines anticléricales, au début du $\mathrm{xx}^{\mathrm{e}}$ 
siècle. La première partie du plan (non chronologique) s'achève par exemple en 1904 avec l'adoption de la loi qualifiée de " charte de l'assistance à l'enfance ", par laquelle le gouvernement républicain marque sa rupture avec les conceptions assistantielles du siècle précédent. Ce découpage chronologique pose une question que l'auteur n'aborde pas de front: dans le domaine de l'histoire des orphelinats et de la prise en charge de l'enfance malheureuse, l'arrivée des républicains au pouvoir dans le dernier tiers du $\mathrm{XIX}^{\mathrm{e}}$ siècle constitue-elle véritablement une rupture ? Si oui, à quel moment celle-ci doit être située (en 1870, avec l'instauration de la Troisième République; en 1879, avec l'arrivée des républicains opportunistes au pouvoir; en 1881-1882, avec la promulgation des lois scolaires ; en 1901, avec l'adoption de la loi « relative au contrat d'association "; en 1904, avec la suppression de l'enseignement congréganiste; en 1905, avec la séparation des Églises et de l'État...) ? Mathieu Peter sous-entend que l'instauration de la Troisième République n'introduit pas de rupture fondamentale dans l'histoire des orphelinats : « si les vingt dernières années du XIX siècle se caractérisent par une défiance envers les congrégations religieuses, l'instauration d'un régime tutélaire n'est pas pour autant une innovation républicaine. [...] Seule change la rigueur du contrôle étatique» (p.137). C'est bien plutôt le projet de sécularisation et de démocratisation de la société, initié par les républicains au début des années 1880 et culminant en 1901-1905, qui introduit une rupture dans l'histoire de la prise en charge de ces institutions à la fois ambiguës et immuables que sont les orphelinats : il remet en question les rapports entretenus par l'État et l'Église, dans un domaine ayant longtemps entremêlé les secteurs public et privé. 